\title{
Blending In: The Presentation of Self among Homeless Men in a Gentrifying Environment
}

\author{
Amy Donley and Emmanuel Jackson ${ }^{1}$
}

Recently there has been an increase in the numbered of unsheltered homeless people in the United States. As a result, more homeless people are on the streets and thus are more visible to the domiciled population. The current project examines whether homeless men in Sanford, Florida experience stigma as a result of their homeless status. It explores the techniques, if any, these men use to downplay their homelessness in order to be viewed as "normal" by domiciled individuals and to blend in with the larger community. In all, thirty men participated in semi-structured, qualitative interviews. The findings indicate that homeless individuals, specifically in the context of an urban area in the midst of gentrification, are aware of the stigma attached to their status and that they are not welcome in their community. It is also shown that many of the men actively try to conceal their homeless status. The results further reveal that homeless individuals have the desire to be clean and presentable as much as the domiciled individual, however they do not have access to many of the resources that will enable them to maintain a presentable appearance. Moreover, the men use several of the resources the city offers in order to upkeep their appearance as much as possible. We tie our findings to Erving Goffman's theories on stigma and impression management in order to support how homeless individuals are affected by traits stemming from each of the three areas that can result in stigma and how they attempt to conceal their status in society. [Article copies available for a fee from The Transformative Studies Institute. E-mail address: journal@transformativestudies.org Website: http://www.transformativestudies.org (02014 by The Transformative Studies Institute. All rights reserved.]

KEYWORDS: Homelessness, Stigma, Presentation of Self, Gentrification.

\footnotetext{
${ }^{1}$ Amy M. Donley, Ph.D., is the Associate Director of the Institute for Social and Behavioral Sciences and an instructor at the University of Central Florida. Her current research focuses on hunger in suburban areas and the role of the court system in addressing the problem of homelessness in communities. Address correspondence to: Dr. Amy M. Donley, University of Central Florida, 4000 Central Florida Blvd., Orlando, FL 32816; Address correspondence to: Amy M. Donley, e-mail: Amy.Donley@ucf.edu.

Emmanuel Jackson is an undergraduate student in the Department of Sociology at The University of Central Florida. He is a McNair scholar whose current research is examining the factors leading to success among young black males at an underperforming, urban high school.
} 